\title{
Blood pressure, dyslipidemia and inflammatory factors are related to body mass index in scholar adolescents
}

Hanane Ghomari-Boukhatem ${ }^{1}$, Assia Bouchouicha ${ }^{1}$, Khedidja Mekki ${ }^{1}$, Karima Chenni², Mohamed Belhadj ${ }^{3}$, Malika Bouchenak ${ }^{1}$

\begin{abstract}
${ }^{1}$ Laboratoire de Nutrition Clinique et Métabolique, Faculté des Sciences de la Nature et de la vie, Université d'Oran 1 Ahmed Ben Bella, Oran, Algeria

'Laboratoire de Biostatistiques, Faculté de Médecine, Université d'Oran, Oran, Algeria ${ }^{3}$ Service de Médecine Interne, Etablissement Hospitalo-Universitaire EHU, Oran, Algeria
\end{abstract}

Submitted: 1 May 2015

Accepted: 18 June 2015

Arch Med Sci 2017; 13, 1: 46-52

DOI: 10.5114 /aoms.2017.64713

Copyright @ 2016 Termedia \& Banach

\section{Abstract}

Introduction: Obesity is associated with increased occurrence of numerous diseases, including hypertension, dyslipidemia, insulin resistance, diabetes, and atherosclerosis. Blood pressure (BP), dyslipidemia, and inflammation markers and their relationships with body mass index (BMI) were determined in scholar adolescents.

Material and methods: Adolescents $(n=210)$ (sex ratio $G / B=106 / 104$; 11 to 16 years) were recruited in three colleges of Oran city. Anthropometric parameters were measured to classify adolescents as thin (T), normal weight (NW), overweight (OW), or obese (O). Waist circumference (WC) and $\mathrm{BP}$ were measured, and serum glucose, uric acid, urea, lipid parameters, tumor necrosis factor- $\alpha$ (TNF- $\alpha$ ), interleukin-1 $\beta$ (IL-1 $\beta$ ), interleukin-6 (IL-6), C-reactive protein (CRP), insulin, leptin, and adiponectin were analyzed.

Results: Adolescents were classified according to their BMI as T (15\%), NW $(63 \%)$, OW (13\%), and O (9\%). Compared to NW, increased values of WC, BP $(p<0.001)$, and glucose $(p<0.01)$ were noted in OW and $O$ groups. Total cholesterol (TC) level was elevated in $\mathrm{O}$ adolescents $(p<0.01)$. Increased low-density lipoprotein cholesterol (LDL-C) in OW $(p<0.05)$ and $\mathrm{O}(p<0.01)$, and reduced high-density lipoprotein cholesterol (HDL-C) concentrations were noted in both OW and O groups $(p<0.05)$, compared to NW. Elevated triglyceride (TG) values and TG : HDL-C ratio were observed in OW $(p<0.05)$ and $\mathrm{O}(p<0.01)$. High values of uric acid were noted in OW and $\mathrm{O}$ adolescents $(p<0.01)$. Compared to NW, there was no significant difference in IL-1 $\beta$ whereas IL- 6 was elevated in T $(p<0.05)$, OW $(p<0.01)$ and $O(p<$ $0.001)$. Leptin, TNF- $\alpha$, and CRP concentrations were significantly increased $(p<0.001)$, whereas adiponectin values were decreased in both OW and O groups $(p<0.01)$, compared to NW.

Conclusions: Significant associations were noted between WC, BP, dyslipidemia, inflammation markers, and BMI, indicating that both $\mathrm{OW}$ and $\mathrm{O}$ adolescents have a tendency to present metabolic syndrome risk factors.

Key words: adolescent, body mass index, blood pressure, dyslipidemia, inflammation.

\section{Introduction}

Obesity is widely considered to be the greatest public health challenge for the $21^{\text {st }}$ century, because of its role in causing disability and

\author{
Corresponding author: \\ Malika Bouchenak \\ Laboratoire de Nutrition \\ Clinique et Métabolique \\ Faculté des Sciences \\ de la Nature et de la vie \\ Université d'Oran 1 \\ Ahmed Ben Bella \\ BP 1524 El M'Naouer \\ 31000 Oran, Algeria \\ Phone: ++213 770449080 \\ E-mail: bouchenak.malika@ \\ Incm-univoran.com
}


crippling healthcare costs [1]. Childhood obesity has more than quadrupled in adolescents aged $12-19$, increasing from $5 \%$ in 1980 to nearly $21 \%$ in 2012 [2].

Hypertension and atherosclerosis may begin in childhood and adolescents [3-5], and can persist into adulthood [6-8]. This has been attributed to high obesity prevalence, especially when it is predominantly abdominal and associated with the other features of the metabolic syndrome (MS); this phenomenon is well characterized in adults $[9,10]$ and adolescents $[11,12]$.

Indeed, obesity is associated with increased occurrence of numerous diseases, including hypertension, dyslipidemia, insulin resistance (IR), diabetes, and atherosclerosis [13].

Moreover, adipose tissue is not simply a fat storage deposit, but has been recognized as an endocrine organ contributing to the inflammatory process in obese subjects, in both vascular and nonvascular tissues [12, 13], producing various adipocytokines, such as leptin, adiponectin, tumor necrosis factor (TNF)- $\alpha$, interleukin (IL)-6, IL-1 $\beta$, and resistin $[14,15]$.

The plasma adiponectin concentration was negatively correlated with the degree of body fat and IR [16], whereas leptin and C-reactive protein (CRP) plasma concentrations were directly related to obesity severity $[17,18]$, and were significantly correlated with the main variables of MS [18]. Moreover, TNF- $\alpha$ and IL- 6 , secreted by fat cells, induced hepatic synthesis of CRP, and both molecules were associated with obesity and cardiovascular diseases $[19,20]$.

A few studies relating obesity to cardiovascular risk factors have been conducted among adolescents in developing countries [12, 21-23], but there was no study in Algerian adolescents concerning metabolic risk factors, except hypertension [3].

Therefore, the aim of this study was to evaluate blood pressure (BP), dyslipidemia, inflammation markers and hormone profile and their relationships with body mass index (BMI), in scholar adolescents.

\section{Material and methods}

The study was carried out from April 2010 to May 2012 in Oran (West Algeria). A total of 210 adolescents (sex ratio $G / B=106 / 104$ ), aged 11 16 years were recruited from three colleges.

\section{Anthropometric and BP measurements}

Anthropometric measurements were taken at schools by trained operators using standard equipment. Waist circumference (WC) was measured to the nearest $0.1 \mathrm{~cm}$ in a standing position at the midpoint between the lowest rib and the iliac crest and at the end of a normal expiration, using a measuring tape. Body weight (BW) was measured to the nearest $0.1 \mathrm{~kg}$ using a portable scale (Seca, Germany) with minimal clothing and no shoes. Height was measured to the nearest $0.1 \mathrm{~cm}$ using a height bar (2 $\mathrm{m}$, dismantling) without shoes. Body mass index was calculated as weight in kilograms divided by the square of height in meters $\left(\mathrm{kg} / \mathrm{m}^{2}\right)$.

The weight status of each subject was categorized as thin (T), normal weight (NW), overweight $(\mathrm{OW})$, or obese $(\mathrm{O})$, according to the cut-off points adopted by the International Obesity Task Force (IOTF) and international cut-off points for BMI for thinness [24].

Adolescents were defined as $\mathrm{O}$ when their BMI was greater than the $95^{\text {th }}$ percentile, OW with a BMI between the $85^{\text {th }}$ and $95^{\text {th }}$ percentile, and NW with a BMI less than the $85^{\text {th }}$ percentile of the reference values for age and sex.

Blood pressure was measured in a sitting position after a 10 min rest period. The averages of two systolic (SBP) and diastolic (DBP) BP measures were recorded at 5 min intervals.

\section{Blood sampling and analysis}

Blood samples were collected after $12 \mathrm{~h}$ fasting from antecubital venipuncture. All collections were made between 8:00 and 9:00 am. Plasma and serum were collected by low speed centrifugation at $3000 \times \mathrm{g}$ at $4^{\circ} \mathrm{C}$, for $15 \mathrm{~min}$. The samples were separated in aliquots and frozen immediately at $-75^{\circ} \mathrm{C}$, until determination could be performed.

Glucose, uric acid, urea, total cholesterol (TC) and triacylglycerols (TG) were measured by enzymatic colorimetric methods (Spinreact kits, Spain).

High-density lipoprotein cholesterol (HDL-C) was determined after precipitation of chylomicrons, very low-density lipoproteins (VLDL) and low-density lipoproteins (LDL), with phosphotungstic acid and magnesium ions (Spinreact kit, Spain). Concentration of LDL-cholesterol (LDL-C) was calculated using the Friedewald formula [25].

Tumor necrosis factor $\alpha, \mathrm{IL}-6$, and IL- $1 \beta$ were determined in duplicate samples with commercial enzyme-linked immunosorbent assay kits (ELISA) (Cayman Chemical's ACE EIA kit) with a range of 0-250 pg/ml. The lower limit of detection was $3.9 \mathrm{pg} / \mathrm{ml}$ for TNF- $\alpha$ and IL-1 $\beta$, and $7.8 \mathrm{pg} / \mathrm{ml}$ for IL-6. The CRP marker was measured in duplicate samples with an immunometric assay kit (ELISA) (Cayman Chemical's ACE EIA kit) with a range of 0-3000 pg/ml, and with a detection limit of approximately $50 \mathrm{pg} / \mathrm{ml}$.

Adiponectin was measured in duplicate samples with an immunometric assay kit (ELISA) (SPI Bio Bertin Pharma), with a range of $0-10 \mu \mathrm{g} / \mathrm{ml}$ 
and with a limit detection of approximately $7 \mathrm{ng} /$ $\mathrm{ml}$. Similarly, leptin analysis was performed in duplicate samples with an immunometric assay kit (ELISA) (SPI Bio Bertin Pharma), with a range of $0-50 \mathrm{ng} / \mathrm{ml}$, and with a limit of detection of $0.2 \mathrm{ng} / \mathrm{ml}$. Insulin was assayed in duplicate samples for the quantitative measurement of human insulin concentrations in serum (ELISA) (abcam) with a range of $0-300 \mu \mathrm{IU} / \mathrm{ml}$ and with a limit of detection of $4 \mu \mathrm{lU} / \mathrm{ml}$.

\section{Statement of ethics}

Informed written consent was obtained from the parents or tutors, and verbal consent was provided by each adolescent. The study was approved by the Preventive Directory of the Ministry of Health.

\section{Statistical analysis}

Statistical analysis was performed using IBM SPSS Statistics version 20. All values were expressed as mean \pm SD. The Shapiro-Wilk test was used to verify whether variable distribution was normal. Differences according to BMI classification were determined by analysis of variance (ANOVA). The Student $t$-test was used to compare different variables in T, OW and $\mathrm{O}$ groups with those of NW. The level of significance was set as $p<0.05$. Correlations between variables were calculated using Pearson's coefficient. The odds ratio (OR) was estimated for each factor separately to evaluate its influence on BMI. A $p$-value $=0.05$ was considered statistically significant with the confidence interval (CI) 95\%. Odds ratio was estimated using logistic regression analysis.

\section{Results}

The characteristics of adolescents according to BMI are presented in Table I. The adolescent classification showed that $15 \%$ were T, $63 \%$ had NW, $13 \%$ were OW and $9 \%$ were O (Table I). There was no significant difference according to age or gender between the different groups. However, BW $(\mathrm{kg})$ was higher in OW $(p<0.05)$ and $\mathrm{O}$ groups $(p<0.01)$ than in NW, whereas no significant difference in height was noted between all the

Table I. Characteristics of adolescents according to BMI

\begin{tabular}{|c|c|c|c|c|c|}
\hline Parameter & Thin $(T)$ & $\begin{array}{c}\text { Normal weight } \\
(\mathrm{NW})\end{array}$ & $\begin{array}{l}\text { Overweight } \\
\text { (OW) }\end{array}$ & Obese (0) & $P$-value \\
\hline Adolescents, $n$ (\%) & $31(15)$ & $133(63)$ & $27(13)$ & $19(9)$ & \\
\hline Boys/girls & $16 / 15$ & $67 / 66$ & $13 / 14$ & $10 / 9$ & \\
\hline Age [years] & $12 \pm 1$ & $12 \pm 1$ & $13 \pm 1$ & $13 \pm 1$ & NS \\
\hline Weight [kg] & $32.1 \pm 3.9$ & $42.2 \pm 8.2$ & $58.7 \pm 7.6^{\star}$ & $74.5 \pm 13.2^{\star *}$ & 0.01 \\
\hline Height $[\mathrm{m}]$ & $1.5 \pm 0.1$ & $1.5 \pm 0.1$ & $1.5 \pm 0.1$ & $1.6 \pm 0.1$ & NS \\
\hline $\begin{array}{l}\text { Pubertal status } \\
\text { I/II/III/IV/V }\end{array}$ & $1 / 3 / 8 / 11 / 8$ & $13 / 17 / 33 / 39 / 1$ & $1 / 4 / 8 / 10 / 4$ & $1 / 3 / 6 / 4 / 5$ & NS \\
\hline $\mathrm{BMI}\left[\mathrm{kg} / \mathrm{m}^{2}\right]$ & $15.0 \pm 0.5^{*}$ & $18.6 \pm 1.8$ & $24.2 \pm 1.9^{* * *}$ & $30.4 \pm 3.1^{\star \star *}$ & $<0.001$ \\
\hline Waist circumference $[\mathrm{cm}]$ & $66.6 \pm 4.3^{*}$ & $72.6 \pm 8.9$ & $89.2 \pm 5.1^{\star * *}$ & $99.2 \pm 3.5^{* * *}$ & $<0.001$ \\
\hline Systolic BP [mm Hg] & $104 \pm 6^{*}$ & $114 \pm 5$ & $127 \pm 4^{\star * *}$ & $138 \pm 5^{* * *}$ & $<0.001$ \\
\hline Diastolic BP [mm Hg] & $58 \pm 5^{*}$ & $63 \pm 6$ & $75 \pm 6^{* * *}$ & $83 \pm 4^{* * *}$ & $<0.001$ \\
\hline Glucose $[\mathrm{mmol} / \mathrm{l}]$ & $4.0 \pm 0.7$ & $4.0 \pm 0.8$ & $4.6 \pm 0.7^{\star \star}$ & $4.8 \pm 0.7^{\star \star}$ & 0.06 \\
\hline $\mathrm{TC}[\mathrm{mmol} / \mathrm{l}]$ & $4.1 \pm 0.9$ & $4.3 \pm 0.9$ & $4.3 \pm 0.6$ & $5.0 \pm 0.8^{* *}$ & 0.04 \\
\hline $\mathrm{HDL}-\mathrm{C}[\mathrm{mmol} / \mathrm{ll}]$ & $1.2 \pm 0.3$ & $1.2 \pm 0.2$ & $1.1 \pm 0.3^{*}$ & $1.1 \pm 0.2^{*}$ & $<0.001$ \\
\hline LDL-C [mmol/I] & $2.4 \pm 0.6$ & $2.5 \pm 0.8$ & $2.9 \pm 0.5^{\star}$ & $3.3 \pm 0.7^{\star *}$ & $<0.001$ \\
\hline $\mathrm{TG}[\mathrm{mmol} / \mathrm{l}]$ & $0.8 \pm 0.4$ & $1.0 \pm 0.4$ & $1.5 \pm 0.5^{\star}$ & $1.7 \pm 0.4^{\star \star}$ & $<0.001$ \\
\hline Urea $[\mathrm{mmol} / \mathrm{l}]$ & $4.1 \pm 1.2$ & $3.8 \pm 1.4$ & $4.2 \pm 1.0$ & $2.8 \pm 1.0$ & NS \\
\hline Uric acid $[\mu \mathrm{mol} / \mathrm{l}]$ & $229.1 \pm 82.9$ & $236.1 \pm 101.6$ & $260.4 \pm 80.7^{\star \star}$ & $255.1 \pm 87.2^{\star *}$ & $<0.001$ \\
\hline Insulin $[\mu \mathrm{IU} / \mathrm{ml}]$ & $6.2 \pm 0.4$ & $6.1 \pm 0.2$ & $6.1 \pm 0.4$ & $6.3 \pm 0.5$ & NS \\
\hline TG/HDL-C & $0.6 \pm 0.1$ & $0.8 \pm 0.1$ & $1.3 \pm 0.2^{*}$ & $1.6 \pm 0.2^{\star \star}$ & $<0.001$ \\
\hline
\end{tabular}

$B M I$ - weight $(\mathrm{kg}) /$ height $\left(\mathrm{m}^{2}\right), B P$ - blood pressure, $T C$ - total cholesterol, HDL-C - high-density lipoprotein-cholesterol, LDL-C - lowdensity lipoprotein-cholesterol, TG - triglycerides. Values are mean $\pm S D$ of 210 adolescents. Differences according to BMI classification were determined by ANOVA. Student t-test: NW vs. T, OW, $0 .{ }^{*} p<0.05 ;{ }^{* *} p<0.01 ;{ }^{* * *} p<0.001$. 
Table II. Inflammatory biomarkers according to BMI

\begin{tabular}{|c|c|c|c|c|c|}
\hline Parameter & Thin & Normal weight & Overweight & Obese & $P$-value \\
\hline IL-1 $\beta[\mathrm{pg} / \mathrm{ml}]$ & $15.3 \pm 5.9$ & $19.6 \pm 11.9$ & $12.9 \pm 11.9$ & $17.6 \pm 11.3$ & NS \\
\hline IL-6 [pg/ml] & $38.7 \pm 7.4^{*}$ & $35.9 \pm 8.1$ & $40.2 \pm 7.5^{\star *}$ & $43.8 \pm 19.2^{* * *}$ & $<0.001$ \\
\hline Leptin [ng/ml] & $3.9 \pm 0.9^{\star}$ & $6.4 \pm 1.7$ & $24.3 \pm 4.9^{\star \star *}$ & $40.9 \pm 5.0^{\star \star *}$ & 0.001 \\
\hline Adiponectin [ng/ml] & $2.5 \pm 1.0^{*}$ & $2.3 \pm 0.9$ & $1.1 \pm 0.5^{\star *}$ & $1.1 \pm 0.5^{\star *}$ & 0.001 \\
\hline TNF- $\alpha[\mathrm{pg} / \mathrm{ml}]$ & $4.9 \pm 1.7^{\star}$ & $7.5 \pm 2.7$ & $10.9 \pm 2.6^{* \star \star}$ & $13.9 \pm 1.3^{* * *}$ & $<0.001$ \\
\hline CRP [pg/ml] & $0.4 \pm 0.1$ & $0.5 \pm 0.1$ & $1.1 \pm 0.5^{\star \star \star}$ & $1.1 \pm 0.5^{\star \star \star}$ & 0.001 \\
\hline
\end{tabular}

IL-1 $\beta$-interleukin-1 $\beta, I L-6$ - interleukin-6, TNF- $\alpha$-tumor necrosis factor, CRP-C-reactive protein. Values are mean $\pm S D$ of 210 adolescents (sex ratio girls/boys, 106/104). Differences according to BMI classification were determined by ANOVA. NS - not statistically significant. Student $t$-test NW vs. T, OW, $0 .{ }^{*} p<0.05 ;{ }^{* *} p<0.01 ;{ }^{* * *} p<0.001$.

groups. Nevertheless, WC increased in both OW and $\mathrm{O}(p<0.001)$, and diminished in $\mathrm{T}(p<0.05)$, compared to NW.

Systolic and diastolic BP were significantly increased in OW and $\mathrm{O}$ groups $(p<0.001)$, and were reduced in T adolescents $(p<0.05)$.

Glucose concentrations were higher in OW and $\mathrm{O}$ than in NW $(p<0.01)$. Total cholesterol values increased in $\mathrm{O}$ adolescents $(p<0.01)$. Moreover, high LDL-C in OW $(p<0.05)$ and $\mathrm{O}(p<0.01)$, and low $\mathrm{HDL}-\mathrm{C}$ levels in both OW and $\mathrm{O}$ groups $(p<0.05)$ were observed, compared to NW (Table I). Triacylglycerols values were higher in OW $(p<0.05)$ and $\mathrm{O}(p<0.01)$ than in NW. Indeed, TG/HDL-C represented $1.3 \pm 0.2$ and $1.6 \pm 0.2$ in $\mathrm{OW}$ and $\mathrm{O}$ versus $0.6 \pm 0.1$ in $\mathrm{T}$, compared to $0.8 \pm 0.1$ in NW.

There was no significant difference in urea and insulin concentrations, whereas uric acid values were elevated in OW and $\mathrm{O}$ adolescents $(p<0.01)$.

Inflammatory biomarkers are presented in Table II. While IL-1 $\beta$ was not significantly different, IL-6, leptin, TNF- $\alpha$, and CRP concentrations were increased $(p<0.001)$, whereas adiponectin values were reduced $(p<0.01)$, in both OW and O groups, compared to NW.

Strong relationships were found between WC, SBP, DBP, LDL-C, TC, TG, leptin and BMI. Inversely, negative correlations were noted between HDL-C, adiponectin and BMI (Table III).

Multiple regression analysis of $B M I$ versus metabolic risk markers (WC, TC, LDL-C, HDL-C, TG, leptin, adiponectin, TNF- $\alpha$ and (RP) is shown in Table IV.

\section{Discussion}

The aim of this study was to evaluate BP, dyslipidemia, inflammation markers and hormone profile and their relationships with BMI, in scholar adolescents.

Anthropometric classification showed that more than half of adolescents presented normal weight, whereas both $\mathrm{T}$ and $\mathrm{OW}$ groups were approximately similar, and O represented $9 \%$. Significant relationships were found between BW, WC, and BMI, as noted in several studies in adolescents [25-27].

Overweight is an important cardiovascular risk factor. Although the clinical manifestations of cardiovascular diseases occur in adulthood, studies have demonstrated that comorbidities, such as dyslipidemia, hypertension, and IR, may be present in childhood and adolescence [28, 29]. Indeed, our study showed that high SBP and DBP values were noted in $72 \%$ of $\mathrm{OW}$ and $\mathrm{O}$, compared to

Table III. Pearson correlation between BMI and studied parameters

\begin{tabular}{|c|c|c|}
\hline Parameter & $r$ & $P$-value \\
\hline Waist circumference & 0.71 & $<0.001$ \\
\hline Systolic BP & 0.50 & $<0.001$ \\
\hline Diastolic BP & 0.75 & $<0.001$ \\
\hline Glucose & 0.06 & 0.064 \\
\hline TC & 0.179 & 0.009 \\
\hline HDL-C & -0.193 & 0.005 \\
\hline LDL-C & 0.24 & $<0.001$ \\
\hline TG & 0.65 & $<0.001$ \\
\hline TG/HDL-C & 0.71 & $<0.001$ \\
\hline Urea & -0.13 & NS \\
\hline Uric acid & -0.008 & NS \\
\hline Insulin & 0.116 & NS \\
\hline IL-1 $\beta$ & -0.070 & NS \\
\hline IL-6 & -0.075 & NS \\
\hline Leptin & 0.74 & $<0.001$ \\
\hline Adiponectin & -0.267 & 0.001 \\
\hline TNF- $\alpha$ & 0.136 & NS \\
\hline CRP & -0.064 & NS \\
\hline
\end{tabular}

NS - not statistically significant. 
Table IV. Multiple regression analysis: association between BMI and metabolic risk markers

\begin{tabular}{|c|c|c|c|}
\hline Parameter & OR & $95 \% \mathrm{Cl}$ & $P$-value \\
\hline Age & 1.07 & $0.79-1.45$ & NS \\
\hline Sex & 0.98 & $0.44-2.12$ & NS \\
\hline Waist circumference & 1.33 & $1.22-1.46$ & $<0.001$ \\
\hline DBP & 3.23 & $3.80-10.2$ & $<0.001$ \\
\hline SBP & 2.95 & $2.41-11.2$ & $<0.001$ \\
\hline Glucose & 1.45 & $0.86-2.42$ & NS \\
\hline TC & 2.23 & $1.36-3.65$ & 0.001 \\
\hline HDL-C & 1.22 & $0.69-0.94$ & 0.009 \\
\hline LDL-C & 1.12 & $1.05-1.19$ & $<0.001$ \\
\hline TG & 1.34 & $1.19-1.50$ & $<0.001$ \\
\hline Uric acid & 1.001 & $0.99-1.00$ & NS \\
\hline Insulin & 1.01 & $0.95-1.28$ & NS \\
\hline IL-1 $\beta$ & 1.011 & $1.01-1.03$ & NS \\
\hline IL-6 & 1.006 & $0.86-1.02$ & 0.621 \\
\hline Leptin & 3.78 & $1.61-8.92$ & 0.002 \\
\hline Adiponectin & 0.98 & $0.96-1$ & 0.04 \\
\hline TNF- $\alpha$ & 2.11 & $1.69-2.62$ & $<0.001$ \\
\hline CRP & 1.22 & $1.14-1.30$ & $<0.001$ \\
\hline
\end{tabular}

$6.5 \%$ of NW and T. These results are in accordance with those of Mexican [4], and East Algerian adolescents [3].

Furthermore, our results showed that TC and TG levels were more elevated in $\mathrm{O}$. Indeed, increased LDL-C but lowered HDL-C were observed with $\mathrm{BMI}(p<0.001)$. These results are similar to those of Brazilian [11] and Japanese studies [30], which have shown that more overweight children presented significant high TG and low HDL-C values, but no relationship was noted between TC, LDL-C and BMI.

Lipid metabolism disorders, such as high LDL-C and low HDL-C, in children were reported as predictors of future atherosclerosis [31]. A report on increased HDL-C suggests the possibility of an association with a lower rate of mortality from ischemic cardiac disease, in Spanish children, compared with other developed countries [32].

In the pediatric population, TG : HDL-C ratio is related to $I R$ and chronic inflammation [33, 34], suggesting that this marker was able to reflect cardiometabolic status, or the risk of developing cardiometabolic disease, later in life [35]. In our study, this ratio was increased with BMI
( $p<0.001)$. Uric acid, which is considered as a cardiometabolic risk factor [36], was increased in our $\mathrm{OW}$ and $\mathrm{O}$ adolescents, compared to NW.

Our results showed that $\mathrm{OW}$ and $\mathrm{O}$ adolescents presented a number of metabolic risk factors, such as high values of WC, BP, TG, LDL-C, TG : HDL-C, uric acid, and low HDL-C.

Moreover, inflammation markers, such as IL-6 and CRP levels, were elevated in OW and $\mathrm{O}$ adolescents. The high CRP concentrations in obese subjects might be explained by the expression of the cytokine IL- 6 in adipose tissue [37] and its release into the circulation [38]. Indeed, IL-6 is a proinflammatory cytokine that stimulates the production of CRP in the liver.

On the other hand, increased TNF- $\alpha$ and lowered adiponectin values were observed relating to BMI. Tumor necrosis factor $\alpha$ produced by white adipose tissue is markedly up-regulated in obesity and contributes to IR [39], possibly through down-regulation of GLUT-4, and inhibition of insulin receptor function and signaling [19]. Rubin et al. [40] suggested that high TNF- $\alpha$ concentrations inhibited adiponectin production, inducing overweight with IR during adolescence. Indeed, adiponectin is an anti-inflammatory and antiatherogenic hormone, exclusively synthesized in adipose tissue [41], with decreased levels in obese subjects $[42,43]$. In our study, adiponectin values were significantly lower in OW and $\mathrm{O}$ adolescents, and in versely correlated with $\mathrm{BMI}(r=-0.2, p<0.001)$.

Obesity was frequently associated with high plasma leptin concentration, which was correlated with IR and MS [44]. Leptin has been shown to be an independent risk factor for coronary heart diseases [45]. In our study, both OW and O groups had increased leptin levels, which was significantly associated with BMI $(r=0.74, p<0.001)$.

The multivariate analysis revealed no significant association between age, gender, glucose, insulin, IL-1 $\beta$, IL-6, uric acid, and BMI. However, relationships were observed with WC, SBP, DBP, TC, LDL-C, TG, TNF- $\alpha$, CRP, leptin $(p<0.001), \mathrm{HDL}-\mathrm{C}$ $(p=0.009)$, adiponectin $(p=0.04)$, and BMI.

This study has some limitations. Initially, the recruited obese group represented 50 adolescents, but only $38 \%$ of them agreed to participate in this study, resulting in a small sample size. Some results did not reach or were bordering on statistical significance. Therefore, further detailed studies, based on a larger population, are needed, for more comprehensive investigation.

In conclusion, this study shows a significant association between WC, BP, dyslipidemia, TNF- $\alpha$, CRP, leptin, and BMI, indicating that both $\mathrm{OW}$ and $\mathrm{O}$ adolescents had a tendency to present MS risk factors.

Future studies are needed to better understand relationships in adolescents with and without 
risk factor clustering to gain insight into prevention and/or treatment of high risk progression to chronic diseases over time.

The findings also highlight the need for longitudinal surveys to track the obesity development related to cardiometabolic diseases.

\section{Acknowledgments}

This work was a part of National Program of Health Research No. 153 and was funded by the General Directory of Scientific Research and Technology Development (DGRS-DT) of the Ministry of Higher Education and Scientific Research.

\section{Conflict of interest}

The authors declare no conflict of interest.

\section{References}

1. Wang YC, McPherson K, Marsh T, Gortmaker SL, Brown $M$. Health and economic burden of the projected obesity trends in the USA and the UK. Lancet 2011; 378: 815-25.

2. Ogden C, Carroll L, Kit B, Flegal A. Prevalence of childhood and adult obesity in the United States, 2011-2012. J Am Med Assoc 2014; 311: 806-14.

3. Benmohammed K, Nguyen MT, Khensal S, Valensi P, Lezzar A. Arterial hypertension in overweight and obese Algerian adolescents: role of abdominal adiposity. Diab Metab 2011; 37: 291-7.

4. Sanchez-Zamorano LM, Salazar-Martinez E, Anaya-Ocampo R, Lazcano-Ponce E. Body mass index associated with elevated blood pressure in Mexican school-aged adolescents. Prev Med 2009; 48: 543-8.

5. Mccrindle BW. Assessment and management of hypertension in children and adolescents. Nat Rev Cardiol 2010; 7: 155-63.

6. Chen X, Wang Y. Tracking of blood pressure from childhood to adulthood. A systematic review and meta-regression analysis. Circulation 2008; 117: 3137-80.

7. Zieske AW, Tracy R, McMahan C, et al. Elevated serum C-reactive protein levels and advanced atherosclerosis in youth. Arterioscler Thromb Vasc Biol 2005; 25: 1237-43.

8. Li S, Chen W, Srinivasan S, et al. Childhood cardiovascular risk factors and carotid vascular changes in adulthood: the Bogalusa Heart Study. J Am Med Assoc 2003; 290: 2271-6.

9. Gami A, Witt B, Howard D, et al. Metabolic syndrome and risk of incident cardiovascular events and death: a systematic review and meta-analysis of longitudinal studies. J Am College Cardiol 2007; 49: 403-14.

10. Haffner S. Abdominal adiposity and cardio-metabolic risk: do we have all the answers? Am J Med 2007; 9: S10-6.

11. Rizzo AC, Goldberg TB, Wlazel RN, et al. Metabolic syndrome risk factors in overweight, obese, and extremely obese Brazilian adolescents. Nutr J 2013; 12: 19.

12. Zaki ME, El-Bassyouni H, El-Gammal M, Kamal S. Indicators of the metabolic syndrome in obese adolescents. Arch Med Sci 2015; 11: 92-8.

13. De Onis M, Martinez-Costa C, Nunez F. Association between WHO cut-offs for childhood overweight and obe- sity and cardiometabolic risk. Public Health Nutr 2012; 16: 625-30.

14. Ben Ounis O, Elloumi M, Lac G, et al. Two-month effects of individualized exercise training with or without caloric restriction on plasma adipocytokine levels in obese female adolescents. Ann Endocrinol 2009; 70: 235-41.

15. Funahashi T, Nakamura T, Shimomura I, et al. Role of adipocytokines on the pathogenesis of arthrosclerosis in visceral obesity. Int Med 1999; 38: 202-6.

16. Reinehr T, Roth C, Menke T, Andler W. Adiponectin before and after weight loss in obese children. J Clin Endocrinol Metabolism 2004; 89: 3790-4.

17. Baskin D, Blevins J, Schwatz M. How the brain regulates food intake and body weight: the role of leptin. J Pediatr Endocrinol Metabol 2001; 14: 1417-29.

18. Valle M, Martos R, Gascón F, et al. Low-grade systemic inflammation, hypoadiponectinemia and a high concentration of leptin are present in very young obese children, and correlate with metabolic syndrome. Diab Metabol 2005; 31: 55-62.

19. Wang S, Reed DB, Goli S, Goswami D. Blood leptin and C-reactive protein provide more sensitive assessment than blood lipids and other inflammatory biomarkers in overweight university students. Nutr Res 2011; 31: 586-93.

20. Hotamisligil G. Mechanisms of TNF-alpha induced insulin resistance. Exp Clin Endocrinol Diabetes 1999; 107: 119-25.

21. Morabia A, Abel T. World Health Organization. Preventing chronic diseases a vital investment. Sozial Praventiv Medizin 2006; 51: 74.

22. Januszek-Trzciakoska A, Malecka-Tendera E, Klimek K, Matusik P. Obesity risk factors in a representative group of Polish prepubertal children. Arch Med Sci 2014; 10: 880-5.

23. Kyriazis I, Rekleiti M, Saridi M, et al. Prevalence of obesity in children aged 6-12 years in Greece: nutritional behaviour and physical activity. Arch Med Sci 2012; 8: 859-64.

24. Cole T, Bellizzi M, Flegal K, Dietz W. Establishing a standard definition for child overweight and obesity worldwide: international survey. Br Med J 2000; 320: 1240-3.

25. Friedewald W, Levy R, Fredrickson S. Estimation of the concentration of low-density lipoprotein cholesterol in plasma, without use of the preparative ultracentrifuge. Clin Chemistry 1972; 18: 499-502.

26. Camhi S, Katzmarzyk P. Prevalence of cardiometabolic risk factor clustering and body mass index in adolescents. J Pediatrics 2011; 159: 303-7.

27. Bindler RJ, Bindler RC, Daratha K. Biological correlates and predictors of insulin resistance among early adolescents. J Pediatr Nursing 2013; 28: 20-7.

28. Backer J, Olsen L, Sorensen T. Childhood body mass index and the risk of coronary heart disease in adulthood. New Engl J Med 2007; 357: 2329-37.

29. Bao W, Threefoot S, Srinivasan S, Berenson G. Essential hypertension predicted by tracking of elevated blood pressure from childhood to adulthood: the Bogalusa Heart Study. Am J Hypertension 1999; 8: 657-65.

30. Fujii C, Sakakibarab H. Association between insulin resistance, cardiovascular risk factors and overweight in Japanese schoolchildren. Obes Res Clin Practice 2012; 6: 1-8.

31. McGill H, McMahan C, Zieske A, et al. Associations of coronary heart disease risk factors with the intermediate lesion of atherosclerosis in youth. Arteriosc Thromb Vascular Biol 2000; 20: 1998-2004. 
32. Garcés C, Gil A, Benavente M, et al. Consistently high plasma HDL-C levels in children in Spain, a country with low cardiovascular mortality. Metabolism 2004; 53: 1045-7.

33. Quijada Z, Paoli M, Zerpa Y, et al. The triglyceride/ HDL-cholesterol ratio as a marker of cardiovascular risk in obese children: association with traditional and emergent risk factors. Pediatr Diabetes 2008; 9: 446-71.

34. Musso C, Graffigna M, Soutelo J, et al. Cardiometabolic risk factors as apolipoprotein $\mathrm{B}$, triglyceride/HDL-cholesterol ratio and C-reactive protein, in adolescents with and without obesity: cross-sectional study in middle class surburban children. Pediatr Diabetes 2011; 12 229-34.

35. Giannini C, Santoro N, Caprio S, et al. The triglyceride to HDL cholesterol ratio: association with insulin resistance in obese youths of different ethnic backgrounds. Diab Care 2011; 34: 1869-74.

36. Chen LY, Zhu WH, Chen ZW, et al. Relationship between hyperuricemia and metabolic syndrome. J Zhejiang Univ Sci B 2007; 8: 593-8.

37. Fried S, Bunkin D, Greenberg A. Omental and subcutaneous adipose tissues of obese subjects release interleukin-6: depot difference and regulation by glucocorticoid. J Clin Endocrinol Metabol 1998; 83: 847-50.

38. Papanicolaou D, Wilder R, Manolagas S, Chrousos G. The pathophysiologic roles of interleukin- 6 in human disease. Ann Intern Med 1998; 128: 127-37.

39. Ruan $\mathrm{H}$, Lodish $\mathrm{H}$. Insulin resistance in adipose tissue: direct and indirect effects of tumor necrosis factor-alpha. Cytokine Growth Factor Rev 2003; 14: 447-55.

40. Rubin D, McMurray R, Harrell J, et al. The association between insulin resistance and cytokines in adolescents: the role of weight status and exercise. Metabolism 2008; 57: 683-90.

41. Frayn K, Karpe F, Fielding B, Macdonald I, Coppack S. Integrative physiology of human adipose tissue. Int J Obes Relat Metabol Disord 2000; 27: 875-88.

42. Reinehr T, Roth C, Menke T, Andler W. Adiponectin before and after weight loss in obese children. J Clin Endocrinol Metabol 2004; 89: 3790-4.

43. Bottner A, Kratzsch J, Muller G, et al. Gender differences of adiponectin levels develop during the progression of puberty and are related to serum androgen levels. J Clin Endocrinol Metabol 2004; 89: 4053-61.

44. Valle M, Gascón F, Martos R, et al. Relationship between high plasma leptin concentrations and metabolic syndrome in obese pre-pubertal children. Int J Obes Relat Metabol Disord 2003; 27: 13-8.

45. Wallace A, McMahon A, Packard C, et al. Plasma leptin and the risk of cardiovascular disease in the West of Scotland Coronary Prevention Study (WOSCOPS). Circulation 2001; 104: 3052-6. 